\title{
Cahiliye Kavramı Üzerine Felsefi Notlar
}

\section{Burhanettin TATAR*}

\section{Philosophical Remarks on the Notion of Jahiliyyah}

Citation/(C: Tatar, Burhanettin, (2016). Philosophical Remarks on the Notion of Jahiliyyah, Milel ve Nihal, 13 (1), 29-42.

Abstract: The notion of jahiliyyah and the word idol are taken by the Qur'an and hadith mostly to refer to some prohibited and negated forms of belief and behavior which were basically common among the Arabs before the advent of Islam. Thus it refers secondarily to the specific historical period in Arabia before the revelation of the Qur'an. However, in modern period, these words were extended to contain all secular systems and institutions by some projects of so-called 'political Islam'. When we try to analyze them from phenomenological viewpoint, we can have a chance to reveal Arabs' ways of thinking and living before Islam. In doing so, we need to take the modern fact that secular ways of critical thinking employ these notions in the creation of 'other' regarding secular-critical mind.

Key Words: jahiliyyah, idol, Qur'an, secular institution, secular system.

Atıf/C: Tatar, Burhanettin, (2016). Cahiliye Kavramı Üzerine Felsefi Notlar, Milel ve Nihal, 13 (1), 29-42.

Öz: Cahiliye kavramı ve onun içerdiği put kelimesi, Kur'an ve hadislerde belirli bir dönemi göstermekten çok olumsuzlanan inanış ve davranış biçimlerine atıf yapmaktadır. Ancak bu kavram modern zamanlarda özellikle İslam'ın

* Prof. Dr., Ondokuz Mayıs Üniversitesi, İlahiyat Fakültesi, İslam Felsefesi Anabilim Dalı [burhantatar@hotmail.com] 
siyasi projeleri içinde semantik alan açısından hayli esnetilmiştir. Bu kelimelere ilişkin fenomenolojik analiz yapıldığında Kur'an'ın eleştirdiği düşünme ve varolma biçimlerini daha iyi kavrama şansına sahip olabiliriz. $\mathrm{Bu}$ analizleri yaparken söz konusu kelimelerin modern seküler düşünme biçimlerinde hala işlevsel olduğunu dikkatten kaçırmamak gerekmektedir. Anahtar Kelimeler: cahiliye, put, Kur'an, seküler kurum, seküler sistem.

\section{Giriş}

İslam öncesi bazı adet ve davranışların Kur'an'da ve bazı hadis rivayetlerinde "cahil/i/ye" şeklinde nitelenmesi, 'tarihsel süreksizlik' (historical discontinuity) dediğimiz bir duruma yol açmıştır. Öyle ki, gerçekte İslam dininin, daha önce Araplar arasında var olan birçok uygulamayı kısmi revize yoluyla sürdürmesine, yani tarihsel sürekliliğe kısmi onay vermesine karşın, 'cahiliye' tabiri bu sürekliliğin süreksizlik bağlamında yeniden anlamlandırılmasına neden olmuştur. Bir başka deyişle, Kur'an ve hadislerde cahil/i/ye kelimesinin kullanılması, yerleşik bir takım olumsuz uygulamaların ortadan kaldırılmasından veya yasaklanmasından çok daha önemli olarak, tarihsel bilinç içinde bir kırılmaya yol açmıştır. Bu kırılma sayesinde yeni olan (İslam), anlamını eskiye (yerleşik bazı dini, ahlaki, ekonomik uygulamalara) karşı koymakla değil, eskiyi yeniye karşı koymakla itham ederek kazanmaya başlamıştır.

Böylece "cahiliye" şeklinde kavramlaşacak olan ve "cehl" kökünden türeyen "cahil, cahili, cahiliye" (kısaca cahil/i/ye) kelimeleri her şeyden önce 'anlamın kaynağı' sorununa yönelik bir tarihsel strateji hüviyetini kazanır. Bu noktada klasik İslam düşüncesinde yaygın görünen kanaat, İslam'ın anlamını kendinden önceki tarihsel döneme referansla değil, kendisinden hareketle kazandığ yönündedir. Buna göre, İslam öncesi dönem, anlamını İslam'a referansla kazanmak durumundadır. Sonuçta cahiliye kavramı, İslam'ın --doğrusal tarih algısı içinde-- 'konumlandırılan' bir şey değil, 'konumlandırıcı bir güç olduğunu temsil edegelmiştir. Kur'an, cahil/i/ye kelimesinin bu temsil gücünü boşlukta bırakmayarak onu kendi büyük anlatısı içinde güçlendirir. Bu büyük anlatıda, Allah'ın insanlara ilk vahyi ile son vahyi arasında teolojik bir süreklilik olduğu bildirilir ve putperestlik gibi sapkınlıklar, bu teolojik sürekliliği kesintiye uğratma çabası olarak görülür. 
Özellikle klasik Müslüman bilginler arasında kısmen kabul gören "tevkifi dil" anlayışının ${ }^{1}$ kökeni de bu büyük anlatıdır. Bu anlatıya göre, Hz. Âdem'e dilin öğretilmesiyle insanlar gerçekliğin kendisine katıksız referansta bulunmayı, yani bir tür gerçekliğin dilini öğrenmişlerdir. Ancak zamanla kelimelerin referansları değiştirilmiş ve insanların ürettiği illüzyonlar içinde dilin gerçeklikle bağ zayıflamıştır. Bu nedenle İbn Hazm'ın sık sık dile getirdiği üzere, Kur'an vahyi, --dilin hakikati doğrudan bildirmesi suretiyle-- gerçeklikle insanların yüzleştirilmesi hadisesidir. Buna göre İslam öncesi dönemde söylenen / yazılan şiirlerde kullanıldığı şekliyle kelimeleri kriter alarak Kur'an'ı anlamak mümkün değildir. İbn Hazm, bu yaklaşımıyla tarihsel sürekliliği reddederken tam tersine tarihi süreksizliği bir kritere dönüştürür. Bu perspektif içinde Kur'an'ın kullandığı ve ilk dört halife dönemindeki Müslümanların anladığı şekliyle Arapça'dan hareketle daha önceki dilsel kullanımları gözden geçirmek gerekmektedir. Böylece tarihsel süreç ve tarihsel bilinç ters yüz edilmek suretiyle, Kur'an anlamın kaynağı olarak ön plana çıkarılır.

Fark edileceği üzere, tevkifi dil anlayışı, tarihsel süreç ve tarihsel bilincin neden ters yüz edildiğini ve cahiliye kavramının neden anlamın kaynağına işaret edemeyeceğini temellendirmeye çalışan bir yaklaşımdır. Bu yaklaşımda vurgulanan asıl nokta şudur: Cahiliye veya putperestlik dönemleri, Allah'ın Âdem'e isimleri öğretmesiyle başlayan tarihsel sürecin ters yüz edilmesi ve sahte bir tarihsel bilincin ortaya çıkması durumudur. Bir başka deyişle, cahiliye dönemleri 'anlamın kaynağı'nın İlahi olduğunu gözden kaçıracak şekilde sahte bir beşeri anlam kaynağı üretme çabasıdır. Kur'an, zaten ters yüz edilmiş tarihsel süreci ve bilinci yeniden tersine çevirerek kendi asli zeminine oturtmuştur.

Ne var ki, Kur'an ve Hz. Peygamber'in kullandığı şekliyle cahil/i/ye kelimesinin, sadece İslam öncesi bir 'dönem'i nitelendirmemesi, daha çok reddedilen bir takım olaylar ve uygulamalara odaklanması ve bu olay veya uygulamaların Hz. Peygamber döne-

1 Klasik yaklaşımda benimsenen farklı dil anlayışları için bkz. Ramazan Demir, “İbn Hazm'a Göre Dilin Menşei ve İlk Dil Problemi”, Usûl İslam Araştırmaları, Say1 10， 2008, ss. 107-124. http://dergipark.ulakbim.gov.tr/usul/issue/view/5000015994 (31.01.2016) 
minde Müslümanlar arasında kimi zaman ortaya çıkması, bu kelimenin semantik alanının sınırlandırılması sorununu beraberinde getirmiştir. Bu sorun karşısında ortaya çıkan makul görüş, cahiliye kavramının tarihsel olarak belirlenebilir dönem ya da bazı uygulamalardan ziyade, her zaman ortaya çıkması mümkün bir "olumsuz durum ya da imkân"ı gösterdiğidir.² Bu açıdan bakıldığında İslam tarihi, aynı zamanda cahiliye sorununun her an yeniden baş gösterme riskinin tarihidir.

Daha açık deyişle, Kur'an'ın reddettiği kibir, kabilecilik, sahte tanrılar edinme gibi cahili tutumlar İslam toplumlarında bir potansiyel risk olarak durduğu için 'cahiliye' kavramı 'İslam' kelimesinden bağımsız anlamlandırılabilecek halde değildir. Aksine İslam'ın reddettiği bir durum olarak tam da İslam kelimesinin anlam alanına dâhildir. Wittgenstein'ın "dil oyunu" kavramına referansla söylersek, bu durum futbol oyununu tanımlarken elle oynamanın yasak olduğunu belirtmeye benzemektedir. Bu durumda İslam kelimesi, her anlamlandırılma anında kaçınılmaz olarak cahiliye kavramını yeniden kendi alanı içinde üretmek durumundadır. Çok muhtemelen bu yüzden İslam tarihi içinde (özellikle Müslümanların Batı ile askeri, ilmi, ahlaki, siyasi ilişkilerinde) cahiliye kavramı her an anlamı esnetilmekte, uzatılmakta ve dönüştürülmekte olan bir semantik alana sahip olmuştur.

Acaba bu durum, Ehli Sünnet içinde kabul gördüğü şekliyle tevkifi dil anlayışının ima ettiği metafiziksel tutumun yanlışlığını, yani İslam'ı kendisinden hareketle tanımlama çabalarının peşinen başarısızlığını gösteriyor mu? Bu sorunun daha iyi tartışılabilmesi ve anlaşılabilmesi için, onun aşağıdaki bazı hususlarla ilgisini hatırlamak yararlı olacaktır.

İlk olarak, bu soru Eflatuncu (Platoncu) düşünme modelinin İslam düşünce tarihi içindeki etkisiyle ilgilidir. Eflatun'un ideler düzeyi gibi, İslam'ı kendisinden hareketle anlamlandırılacak bir şey

2 Toshihiko Izutsu, God And Man in The Qur'an, Islamic Book Trust, Second Reprint, Malaysia, 2008, ss. 216-251; William E. Shepard, "Sayyid Qutb's Doctrine of "Jāhiliyya", International Journal of Middle East Studies, Vol. 35, No. 4 (Nov., 2003), ss. 521-545; Sayed Khatab, The Political Thought of Sayyid Qutb: The Theory Of Jahiliyyah, (Routledge Studies in Political Islam) 1st Edition, London (2006), ss. 10-43. 
olarak görmek ve cahiliye kavramını mağara içindeki gölgeler düzeyi gibi ele almak, her şeyden önce İslam'ı salt entelektüel (tranzendental) düzeyde temaşa etmek, dolayısıyla onu daha işin başında tarihten, toplumdan, siyasetten, dahası yaşandığı şekliyle din olmaktan uzaklaştırmak değil midir?

Yine bu soru, Mevdudi ve Seyyid Kutup gibi yakın dönem bilginlerin siyasi bağlamda ele aldıkları İslam tasavvuru (Batı literatürü açısından 'siyasi İslam') içinde 'cahiliye' kavramına yükledikleri yeni anlamla bağlantılıdır. Adı anılan bilginlerin temel kalkış noktası --şayet yanlış anlamıyorsak-- İslam ve cahiliyenin son asırlarda artık iyice iç içe girmesi (Mevdudi) veya tüm dünyaya yeni ve ilkinden daha sofistike bir cahiliye döneminin hakim olması nedeniyle (Kutub) yeniden saf İslam'a dönüşün kaçınılmazlığıdır. ${ }^{3} \mathrm{Bu}$ yaklaşım içinde steril (ideal, tranzendental) bir İslam tasarımının kurgulandığı ve cahiliye kavramının, İslam'ın mutlak ötekisi olarak aşılması gereken bir fiili soruna işaret ettiği açıktır.

Ne var ki burada hemen hemen tüm tasarımı bir şekilde biçimlendiren 'put' tasavvuru adeta sınırsızca esnetilmektedir. Daha açık deyişle, İslam öncesi dönemde dini hayat içinde kritik rol oynayan put tasavvuru, modern dünyanın tüm seküler kurumlarını kapsayacak şekilde esnetilmekte ve genişletilmektedir. Buna göre modern cahiliyenin en temel karakteristiği, Allah'ın mutlak hükümranlığının yerini insanların oluşturduğu hukuki, ekonomik, ahlaki sistem ve kurumların almasıdır. Bu yaklaşıma göre, her bir seküler sistem ve kurum modern cahiliye döneminin putlarıdır. Mevdudi ve Seyyid Kutub gibi, bilginlerin 'siyasi bağlamda İslam' projesinin put tasavvurunu modern dünyaya referansla adeta sonsuzca esnetirken, bu esnetme / yorumlamanın kendisini İslam'ın otantik anlamı olarak dikte etmesi, yorumcunun kendisini anlamın kaynağı haline getirmesi, dolayısıyla kendi temel iddiası ('anlamın kaynağ Kur'an'dır') ile çelişmesi değil midir?

Bu projenin --kendi tasavvur alanı içinde-- modern kurumları eski putlar ile özdeşleştirmesi ve bu özdeşleştirme süreci içinde putlara sınırsızca savaş açması (zira bu tasavvura göre putlar her zaman olacaktır), ayn zamanda put ve cahiliye tasavvurunu

3 Sayyed Khatab, Hakimiyyah and Jahiliyyah in the Thought of Sayyid Qutb, Middle Eastern Studies, 38:3, (2002) 145-170. 
doğrudan İslam'ın siyasi tasavvurunun ayrılmaz bir parçası haline getirmek değil midir? Söz konusu bilginlerdeki İslam'ın siyasi tasavvuru, kendi yorumladığı şekliyle modern bir 'put'u kendi ötekisi olarak tanımlarken aynı zamanda bu putu kendisini sürekli var etmek için yeniden üretmek durumunda kalacaktır. Bu ise, kendi yorumunu kalkış noktası haline getirmek ve kısır bir döngü içinde kendi düşmanını kendi içinde üretmek olduğundan, siyasi İslam tasavvuru sürekli kendi kendisiyle mücadele etmek zorunda kalacaktır. Böylece sosyal, siyasi, ahlaki ve hukuki alanda tüm putları yok etme amacıyla yola çıkarken, zihinsel bir putu her an yeniden üretmek durumunda kalmak, aynı zamanda İslam'ı bu zihinsel puta referansla anlamlandırma sorununa yol açmayacak mıdır?

Üçüncü olarak yukarıdaki temel soru, İslam'ı salt kendisiyle tanımlamanın modern dünyada ne tür bir Müslüman tipine yol açabileceği sorusu ile ilgilidir. İslam'ı salt kendisinden hareketle tanımlamaya çalışmak, kaçınılmaz olarak insanın "İslam" diye tanımlanan şeyin ötekisi haline getirilmesi sonucunu doğurmaktadır. $\mathrm{Bu}$ durum ise yine kaçınılmaz olarak çifte yabancılaşma sorununa yol açmaktadır - ki zaten Mevdudi ve Seyyid Kutub gibi bilginlerde bu çifte yabancılaşma sorunu açıkça gözlemlenebilir. Öncelikle, İslam bu dünyaya yabancılaşmaktadır --buna daha önce Platoncu yaklaşıma değinirken işaret etmiştik. İdeler düzeyinin bu dünyaya yabancılığı gibi, kendi kendine tanımlanan İslam bu dünyaya yabancılaşmaktadır. Sonra bu yabancılaştırma sorununu aşmak isteyen Müslüman, kendisini kaçınılmaz biçimde bu dünyaya yabancılaştırmaktadır --tıpkı Platoncu görüşte filozofun ideler düzeyini temaşa etmek istediğinde (mağaradan çıkmaya çalışması durumunda) bu dünyaya yabancılaşması gibi. Bu ise, sonuçta İslam'ın ‘bu dünya için' kategorisiyle zıtlaşacak şekilde İslam'ı kendi tarihsel ilgi alanından önce yoksunlaştırma, sonra statik olarak yeniden kurma eğilimlerini beraberinde getirebilmektedir. Kanaatimizce modern İslam dünyasında var olan fanatik / radikal yaklaşımların veya şiddeti kendi projesinin yegâne aracı haline getiren grupların temel sorunlarından birisi bu çifte yabancilaşma sorunudur.

$\mathrm{Bu}$ analizler sonrasında cahiliye ve bu kavramın içerdiği put tasavvuru hakkında daha farklı bir yaklaşım imkânını araştırabiliriz. Bu noktada yine en genel sorularla işe başlamak yararlı olabilir: 
Kur' an ve hadislerde dile getirilen "cahil/i/ye" nedir? 'Put' tasavvuru fenomenolojik açıdan nasıl ele alınabilir?

$\mathrm{Bu}$ sorular hakkında araştırma yapan hemen tüm bilginlerin vurguladığı üzere, cahil/i/ye kelimesi, her ne kadar ilk elde 'bilgisizlik' anlamına gelse de, tarihsel açıdan 'hilm' in zıddı olarak anlaşılmıştır. Dolayısıyla o, kibirli, bencilliği ahlaki doğrulara tercih eden, düşünmeksizin kendi dogmalarına göre harekete geçen, kabile dayanışmasını hakikate üstün tutan ve bu anlamda barbarlık ruhunu temsil eden insan tipine yönelik bir metafordur. Cahil/i/ye kelimesi böylesi bir insanın evrensel düşünememesi, derin bir ahlaki kaygı taşımadığı için kendi varoluş sorunlarını fark edememesi, yaptığ eylemlerin yol açtığı ve açacağı sorunları öngörememesi anlamında bilgisizliğine de atıf yapar. Sahip olduğu şirk inancının bu dünyada ve ölüm sonrası hayatta ne tür bir sonuç doğuracağına dair her hangi bir eleştirel sorgulaması ve tefekkürü olmadığ 1 için, o insanın kendi sığ dünyası içine sıkışıp kalması anlamında dini bağlamda temelsizliğini ve körlüğünü dile getirir.

$\mathrm{Bu}$ tespitlerden fark edileceği üzere, cahiliye kavramı insanın 'kendisi'yle, 'bu ve öteki dünya' ile ve 'Allah' ile ilişkisindeki köklü sorunlara dikkati çekmektedir. İnsanın kendisine ve kendisiyle bir şekilde özdeşleştirdiği kabilesine aşırı değer atfetmesi, insanın kendisini değerlerin hem kaynağı hem de konusu haline getirmektedir. Ne var ki aynı insan, kendi çıarı söz konusu olduğunda kabile değerlerini veya putlara göstere geldiği saygıyı bir kenara koyabilmektedir. ${ }^{4}$ Kendisiyle ilgili en temel sorunu, kendisini gözden geçirmesine yol açabilecek bir eleştirel bilince sahip olmamasıdır.

Görebildiğimiz kadar Kur'an'ın cahiliye metaforu içinde kendilerine işaret ettiği insanları sık sık akılsızlık, düşüncesizlik, basiretsizlik ve körlükle itham etmesinin temel nedeni bu tür insanlardaki eleştirel düşünce yoksunluğudur. Bu yaklaşım açısından bakıldığında cahiliye metaforu, tek tip, tek katmanlı veya tek boyutlu düşünme biçimine atıf yapmaktadır. Zaten böylesi bir insanın kendisine aşırı değer yüklemesi ile eleştirel düşünce yoksunluğu aynı sorunun iki farklı yüzünü ifşa eder. Eleştirel bilincin

4 Mehmet Mahfuz Söylemez, "Cahiliye Arap İnancında Putların Yeri", Milel ve Nihal, 11 (1), 2014, ss. 9-47. 
olmadığı yerde düşünce insanın kendi tutku, amaç, çıkar ya da benimsediği kabile değerlerine göre şekillenirken, sadece merkezden dışarıya yönelik tek boyutlu bir çizgi halini alır. Bunun anlamı şudur: Böylesi bir insanda düşünce, Heidegger'in tabiriyle söylersek, dünyanın ve içindekilerin el altında kategorisinde görülmesi, hemen her şeyin insanın tasarımları için birer araca dönüştürülmesi, Hegel'in deyimiyle, arzunun tatminine yönelik bir tüketim konusu haline getirilmesi için işlev üstlenir.

Daha dikkatli bakıldığında böylesi bir düşünme tarzı, insanın (kabilenin) kendi benliği ve çıkarı için hemen her şeyin el altında kategorisinde görülmesi anlamında doğrudan düşüncenin sınırlıl1ğına ve bu sınırlılık içinde araçsallaştırılan dünyanın aynı zamanda amaçsallaştırılmasına yol açmaktadır. Zira arzunun tatmini sağlayan şey, aynı zamanda arzunun yeniden var olabilmesi için gereken bir amaçtır. Bu bağlamda cahiliye metaforu, insanın her şeyi araçsallaştırırken aynı zamanda kendisini yeniden üretebilmek (varlığını sürdürebilmek) için araçsallaştırdığı şeyleri kendi önüne bir hedef ya da amaç olarak koyması durumuna dikkatleri yönlendirmektedir. Dolayısıyla araçların birer amaç ve amaçların birer araç olabilmesi anlamında cahiliye metaforu sürekli ters yüz edilmekte olan bir varlık tasavvurunu ima etmektedir.

Konuya odaklanmaya devam ettiğimizde fark edebildiğimiz bir diğer husus, arzu ile arzuyu tatmin eden araç (aynı zamanda onu üreten amaç) bağlamında cahiliye insanının kaçınılmaz olarak 'ikame mantığı' içinde düşünmesidir. Bu mantık içinde harici dünya bir taraftan insanın arzusunu ikame etmekte, arzusuna cevap verebilecek bir şey olarak anlam kazanmaktadır. Diğer taraftan aynı dünya insanın kendi varlığını sürdürebilmesi için hayatının amacını ikame etmekte yani insan, arzuladığı dünyaya göre anlam kazanmaktadır. Dolayısıyla insan dünyayı kendi arzu ve tasarımına göre kurgulama anlamında inşa ederken, dünya da insanı kendi varlık tarzı içinde kurmakta veya inşa etmektedir.

Görebildiğimiz kadarıyla cahiliye metaforu içinde kritik bir nokta olan put tasavvuru, cahiliye insanının ikame mantığı ile yakından ilgilidir. İlk elde put kavramı, insanı Allah'a yaklaştıracak bir vasat ya da eşik olarak anlam kazansa da, daha geride o, cahiliye düşüncesinde merkezi yer tutan ikame mantığının kaçınılmaz bir sonucudur. Kur'an'ın ağır biçimde eleştirdiği put/perestlik, Allah'a 
şirk koşmaktan çok daha önce, cahiliye insanının yeryüzünde ikame mantığ1 içinde var olma tarzına referansta bulunmaktadır. Daha açık deyişle, insanlar putları inşa ve ikame ederlerken aynı zamanda putlar aracılığıyla kendilerini inşa ve ikame etmektedirler. Putlar, cahiliye insanının arzusunu tatmin eden bir araç iken, aynı zamanda onun varlığını sürdürmesini (kendisini yeniden üretmesini) sağlayan bir amaçtır. Bu yüzden putlar insanların arzu ve amaçlarının birer yüklenicisi, taşıyıcısı ve aynası olarak sosyal hayat içinde şahıslaşan, diyalog kurulan, insanların kendileri kadar gerçek olan bir mekân teşkil ederler.

Bu açıdan bakıldığında putlar, genel olarak, ilk elde gayri-insanileştirilen Tanrı'nın (Allah) insanileştirilmesi ve insanileştirilen Tanrı'nın yeniden gayri-insanileştirilmesidir. Bunun anlamı şudur: Putlar, ilk elde erişilmez, ulaşılamaz kabul edilen Tanrı'nın, yine Tanrı'nın verdiği güç aracılığıyla kutsallaşan put sayesinde insanın erişebileceği kısmi bir forma bürünmesi ${ }^{5}$, ancak bu formun mutlak yaratıcı Tanrı'nın kendisi olmaması nedeniyle yeniden formsuzlaştırılmasıdır. Dolayısıyla putlar, gerçek anlamda Tanrı'ya eş tutulan hususlar olmayıp, tersine Tanrı'ya eş tutulamazlığın absürd temsilidirler. Kuşkusuz Cahiliye insanı fiziksel boyutu itibarıyla 'put'a her hangi bir anlam yüklememektedir.

Put, yukarıda belirttiğimiz üzere, insanın arzusunu tatmin edecek şekilde mutlak Tanrı'nın bir nesneye verdiği kudret içinde kısmen formlaştırılması, Tanrı'nın -kudretinin tezahürü açısından-kendisine adeta dokunulabilir bir mesafede konumlandırılmasıdır. Bu anlamda put, özü itibarıyla yabancı olan Tanrı'nın -kudretinin tecelli ettiği nesne içinde - insan için aşina hale getirilmesidir. Ancak kudretin tecelli ettiği nesnenin kendisi kutsal olmadığı için, aynı zamanda aşina hale getirilen Tanrı yeniden insana yabancılaştırılmaktadır. Dolayısıyla formlaştırılan Tanrı, yeniden formdan arınd1rılmaktadır. Kısacası put, Tanrı ile insan arasındaki ilişkileri kurgularken çift yönlü bir ters yüz etme durumuna atıf yapmaktadir.

5 M. M. Söylemez, bu duruma atfen cahiliye Arapları nezdinde putların bir tür Allah'ın yeryüzündeki eli olarak işe gördügüünü belirtir. Bkz. Söylemez, "Cahiliye Arap İnancında Putların Yeri" s. 17. 
Dikkat edilecek olursa, Kur'an böylesi bir bağlamda ele alınan putları doğrudan her hangi bir ciddi eleştiri konusu haline getirmez. Aksine Hz. İbrahim ve onun kırdığ putlara referansta bulunan anlatısında görüleceği üzere ${ }^{6}$, onları tam bir karikatüristik söylem alanı içinde tutar. Bu söylemden hareketle ciddi eleştiri ve uyarısını ikame mantığı içinde Tanrı ile insan arasındaki ilişkileri dilediği gibi kurgulayan cahiliye insanının kendisine yöneltir. Bu yüzden Kur'an açısından şirk ya da putperestlik, Tanrı'ya bir takım nesneleri ortak koşmak değil, aksine insanın kendisini --kendi arzusunun objesi haline getirdiği nesne ya da putlar üzerinden-- Tanrı adına konuşabilme yetkisi ile donatmasıdır. Bu şekilde o, insanın kendi faniliğini, sınırlılığını, bilgisizliğini örtbas edecek şekilde put tasavvuru üzerinden kendisini gizlice kutsallaştırması, yani Tanrı ile ilişkisinin nasıl olacağına kendi başına karar vermesidir. Bu nedenle Kur'an açısından şirk ve putperestlik, sosyal mekândaki putlara tapınma değil, onları put haline getiren insanın kendisini gizli puta dönüştürmesidir.

Geldiğimiz nokta, cahiliye düşüncesindeki en köklü ters yüz olma durumunu fark etmemize imkân vermektedir: Cahiliye insanı kendi sınırlılığı ve faniliğini kabullendiği için erişilmez, ulaşılmaz diye düşündükleri Tanrı'ya seslerini duyurabilecek bir aracı kurgulamışlardır. Ancak tam da bunu yaparlarken, aracının ne olduğuna, gücünün nasıl tezahür edeceğine ve Tanrı katındaki değerine kendi anlatıları içinde karar verdikleri için kendi sınırlılıklarıyla çelişen bir konuma kendilerini yerleştirmişlerdir. Bu durum insanın kendisini ilk önce Tanrı karşısında konumlandırırken, aynı zamanda Tanrı'yı kendi karşısında konumlandırması anlamında bir mantıksal ve teolojik çelişkiye yol açmaktadır.

Dolayısıyla şirk koşma sorunu, gerçekte kutsallaştırılan nesne veya varlıklarla ilgili bir sorun olmayıp, daha ziyade, insanın kendisini Tanrı adına yetki kullanan bir konuma yükseltmesi sorunuyla ilgilidir. Kutsallaştırılan nesne ya da varlıklar, sadece insanın gerçekleştirdiği yetki gaspını gizleyen birer maske görevini görürler. Cahiliye insanındaki kibrin bir nedeni, Tanrı adına Tanrı'nın yetkisini gasp etmesiyle ilgili görünmektedir. Bu nedenle özellikle Mekke'de otorite olan çok sayıdaki cahiliye insanının neden Kur'an

6 Enbiya (21), 57-65. 
vahyine olumsuz tepki verdiğini anlamak mümkündür. Zira Kur'an'ın en temel vurgusu, hiç kimsenin Tanrı adına Tanrı'nın yetkisini gasp edemeyeceğidir.

Bu açıdan bakıldığında, daha önce zikrettiğimiz bazı siyasi bağlamda İslam projelerinde görüldüğü üzere, Kur'an'da ve hadislerde eleştirilen 'cahil/i/ye' ve 'put' tasavvuru ile modern dönemdeki seküler sistem ya da kurumları özdeşleştirmek, her iki kavramın semantik alanının aşırı biçimde esnetilmesi sorununu beraberinde getirmektedir. Zira modern seküler sistem ve kurumların hiç birinde Tanrı adına yetki gaspı yapmak gibi bir iddia söz konusu değildir. Aksine seküler sistem veya kurumlar 'insan adına' ve 'insan için' yetki sahibi olma durumunu temsil ederler. Bu sistem veya kurumların yol açtıkları bir takım dini, ahlaki, kültürel, siyasi ve ekonomik sorunlar farklı bir tartışma konusudur. ${ }^{7}$ Ama işin ilginç yanı 'put' tasavvurunun hem Kur'an'ın söylemlerinde hem de seküler kurum ve sistemlerin kendileri için ürettikleri söylemlerde önemli bir yer tutmasıdır. Kur'an, insanın Tanrı adına yetki gaspını simgeleyen veya ikame eden bir şey olarak putları karikatüristik söylem alanına çekerken, seküler kurum ve sistemler insan aklı ve özgürlügünü gasp edecek şekilde yetki kullanımını put tasavvuru içinde eleştiri konusu haline getirmektedir.

Benzer yaklaşım1, felsefe tarihinde eleştirel düşünceyi temsil eden filozoflarda da bulmaktayız. Sözgelimi Wittgenstein'a göre, felsefenin yapabileceği tek şey putları ortadan kaldırmaktır. Felsefe,

7 Bu tartışma konularından bazıları şunlardır: Tanrı adına Tanrı'nın yetkisini gasp etmek, Tanrı adına toplumda sınırsız bir kontrol alanı oluşturmaya yol açabilir. 'İnsan adına' ve 'insan İçin' yetki alanı oluşturmak ve yetki talep etmek ile toplum üzerindeki nihai yetkinin sadece Allah'a ait olduğunu söylemek ayrı şeylerdir. Hakeza bir başka geleneksel ve bir o kadar modern tartışma konusuna yani "politeizm versus monoteizm" sorununa burada dikkat çekmekte yarar vardır. Zira politeizm savunusu hemen her zaman monoteizmin baskıcı ve şiddeti çoğaltan siyasi-dini bir rejime yol açtı̆ı iddiasını ileri sürmektedir. Bu konuda bkz. Katsuhiro Kohara, "Discourses and Realpolitik on Monotheism and Polytheism", Journal of the Interdisciplinary Study of Monotheistic Religions : JISMOR 2, 2006, ss. 1-16 ; Gregory Price Grieve, "Symbol, Idol And Murti: Hindu God-images and the Politics of Mediation," Culture, Theory and Critique 44 (2003), ss. 57-72. 
yok ettiği putun yerine bir başka put koymamalıdır. ${ }^{8}$ Seküler zeminde ilerleyen sistem, kurum ve düşünme tarzları için put, yetki gaspı anlamına geldiği için aynı zamanda gerçekliğin maskelenmesi durumudur. ${ }^{9}$ Bundan anlaşılacağı üzere, seküler yapılar, yok etmeyi hedefledikleri putları 'öteki' olarak gördükleri farklı bir cahiliye ortamına ait kılmaktadırlar. Kısacası, cahiliye kavramı (ve bu kavram içinde yer tuttuğu şekliyle put tasavvuru), tarihsel ve teknik olarak Kur'an ve hadis kaynaklı olsa da, günümüzde birbirinden çok farklı inanma ve düşünme modelleri içinde üretilmeye müsait bir yapıdadır. ${ }^{10}$ Batı bilim ve felsefesinde eleştirel yaklaşımda bir metafor olarak put (idol) kelimesinin daha ziyade Yahudiliğin kutsal metinlerinden ${ }^{11}$ ilham aldığını yeri gelmişken belirtmeliyiz. ${ }^{12}$

\section{Sonuç}

Cahiliye ve put kelimelerinin hangi perspektiften hareketle yeniden üretildiği ve dolaşıma sokulduğu öncelikle araştırılması gereken bir husustur. Zira birbirini suçlayan iki farklı yaklaşım aynı kavramı harekete geçirebilmektedir. Sözgelimi, IŞíD veya DAIŞ̧ örgütü, Tanrı'nın hükümranlığını tam kabullenmedikleri ve kendisine destek vermedikleri gerekçesiyle geride kalan tüm insanları cahiliye dönemi insanı (kâfir) olarak nitelerken, bir başkası barbarlığı ve Tanrı adına yetki gaspı yaptığı gerekçesiyle IŞi̇'i cahiliye döneminin insan tipi içinde görmektedir.

8 Ludwig Wittgenstein, The Big Typescript, Manuscript 213 and 413, as quoted in Moshe Halbertal and Avishai Margalit, Idolatry, trans. N. Goldblum, Cambridge, Harvard University Press, 1992, s. 244.

9 Detaylı bir analiz için bkz. Janice L. Deary, "A Picture Held Us Captive": Investigations Towards an Iconoclastic Praxeology University of St Andrews thesis. University of St Andrews, 2007.

10 Modern put algisı için bkz. Leora Batnitzky, Idolatry and Representation: The Philosophy of Franz Rosenzweig Reconsidered, Princeton University Press, Princeton, 2000.

11 Bu metinlerdeki put anlayışı için bkz. Brian S. Rosner, "The Concept of Idolatry," Themelios 24.3 (May 1999): 21-30; Daniel C. Harlow, "Idolatry and Alterity:Israel and the Nations in the Apocalypse of Abraham", in The "Other" in Second Temple Judaism. Essays in Honor of John J. Collins, ed. D. C. Harlow, M. Goff, K. M. Hogan, and J. S. Kaminsky, Grand Rapids: Eerdmans, 2011.

12 Bu konuda detaylı bir çalışma için bkz. Moshe Halbertal and Avishai Margalit, Idolatry, trans. N. Goldblum (Cambridge, Harvard University Press, 1992). 


\section{Kaynakça}

Batnitzky, Leora. Idolatry and Representation: The Philosophy of Franz Rosenzweig Reconsidered, Princeton University Press, Princeton, 2000.

Deary, Janice L. "A Picture Held Us Captive": Investigations Towards an Iconoclastic Praxeology University of St Andrews thesis. University of St Andrews, 2007.

Demir, Ramazan Demir, “İbn Hazm’a Göre Dilin Menşei ve İlk Dil Problemi", Usûl İslam Araştırmaları, Sayı 10, 2008, ss. 107-124. http://dergipark.ulakbim.gov.tr/usul/issue/view/5000015994 (31.01.2016)

Grieve, Gregory Price, "Symbol, Idol And Murti: Hindu God-images and the Politics of Mediation," Culture, Theory and Critique 44 (2003), ss. 57-72.

Halbertal, Moshe and Margalit, Avishai. Idolatry, trans. N. Goldblum (Cambridge, Harvard University Press, 1992).

Harlow, Daniel C. "Idolatry and Alterity:Israel and the Nations in the Apocalypse of Abraham", in The "Other" in Second Temple Judaism. Essays in Honor of John J. Collins, ed. D. C. Harlow, M. Goff, K. M. Hogan, and J. S. Kaminsky, Grand Rapids: Eerdmans, 2011.

Izutsu, Toshihiko. God And Man in The Qur'an, Islamic Book Trust, Second Reprint, Malaysia, 2008

Khatab, Sayed. The Political Thought Of Sayyid Qutb: The Theory Of Jahiliyyah, (Routledge Studies in Political Islam) 1st Edition, London (2006), ss. 10-43.

Khatab, Sayyed. "Hakimiyyah and Jahiliyyah in the Thought of Sayyid Qutb", Middle Eastern Studies, 38:3, (2002) 145-170.

Kohara, Katsuhiro, "Discourses and Realpolitik on Monotheism and Polytheism", Journal of the Interdisciplinary Study of Monotheistic Religions : JISMOR 2, 2006, ss. 1-16.

Ludwig Wittgenstein, The Big Typescript, Manuscript 213 and 413, as quoted in Moshe Halbertal and Avishai Margalit, Idolatry, trans. N. Goldblum, Cambridge, Harvard University Press, 1992. 
Burhanettin TATAR

Rosner, Brian S. "The Concept of Idolatry," Themelios 24.3 (May 1999): 21-30.

Shepard, William E. "Sayyid Qutb's Doctrine of "Jāhiliyya", International Journal of Middle East Studies, Vol. 35, No. 4 (Nov., 2003), ss. $521-545$

Söylemez, Mehmet Mahfuz, "Cahiliye Arap İnancında Putların Yeri", Milel ve Nihal, 11 (1), 2014, ss. 9-47. 